\title{
Levels of Toxic Metals in Skin Lightening Agents Marketed in Nigeria
}

\section{DOI: https://doi.org/10.24297/jac.v16i0.8317}

\author{
${ }^{* 1}$ Moses Olayemi Akiibinu, ${ }^{1}$ Olutola Bob Soile, ${ }^{1}$ Lilian Esther Akinade, ${ }^{2}$ Susan Olufunmilayo Akiibinu \\ ${ }^{1}$ Department of Biochemistry and Chemistry, College of Pure and Applied Sciences, Caleb University Lagos, \\ Nigeria,
}

\author{
${ }^{2}$ Department of Nursing Services, University College Hospital, Ibadan, Nigeria. \\ akiibinumoses@yahoo.com
}

\begin{abstract}
:
Background: Bleaching agents produced by registered companies in developed countries have regulated concentrations. But various local skin lightening agents produced in Africa, especially Nigeria have no identified active agent. This study determined the levels of potentially toxic heavy metals constituents of bleaching agents commonly used by Nigerians.
\end{abstract}

Methods: Twelve different types of skin lightening creams (Extra white, Make me white, Extract, Perfect white, UV lightening, Pure skin, Body treat, Dodo up, Bronze tone, White express, Peau Claire and Otentika) available Nigerian markets were randomly collected based on their usage and availability. Three non- lightening creams served as the controls for this study. Levels of mercury, lead, cadmium, chromium and arsenic were determined in both lightening and non- lightening creams (controls) using atomic absorption spectrophotometer (AAS).

Results: All lightening creams 12/12 $(100 \%)$ contained significantly $(p<0.05)$ higher levels of mercury compared with the control. $11 / 12(91.7 \%)$ of the lightening creams contained significantly ( $p>0.05)$ higher levels of lead compared with the control. Levels of arsenic were significantly $(p<0.05)$ higher in $11 / 12(91.7 \%)$ of the lightening creams compared with control. Levels of cadmium increase significantly $(p<0.05)$ in $4 / 12(22.92 \%)$ of the lightening creams compared with the control. 4/12 (22.92\%) of the lightening creams contained significantly $(p<0.05)$ higher levels of chromium compared with control.

Conclusion: It may be concluded that mercury, cadmium, lead and arsenic are common constituents of lightening creams marketed in Nigeria. To avert the risk and consequences of metal toxicity in the use of the lightening agents, levels of toxic metals should be monitored officially in cosmetics (e.g. creams), while the manufacturers are educated about the potential risks associated with higher levels of these metals. This study could therefore provide valuable information for health researchers and policy makers.

Keywords: Toxic metals, skin lightening agents

\section{Introduction:}

Skin bleaching is a purposeful lightening of the skin, pigment removal or body beautification by using chemicals [1]. It can lead to permanent or temporary alteration of the color of the outer layer (epidemics) of the skin [2]. This practice cuts across all ages, races, beliefs and ideologies. Even the white race that might claim advantage over others still engage in skin bleaching, probably as a method of maintaining their body color or for other purposes. African women are among the most widely represented users of skin-lightening products because of a belief that fair skin leads to beauty than dark skin [3]. A large fraction of the population, primarily women and young girls in Asia, Africa and Latin America use skin lighteners. Nevertheless, the young female adolescents have been identified as most prone to skin bleaching practice [4]. Survey reports these figures of users in specific countries; Senegal $27 \%$, Mali $25 \%$, Togo $59 \%$, South Africa $35 \%$, Nigeria $77 \%$, Hong Kong $45 \%$, Republic of Korea $28 \%$, Malaysia $41 \%$, Philippines $50 \%$ and Taiwan $37 \%$. Reason given by $61 \%$ of the respondents to the survey is that they felt younger with a fair complexion [5]. The users believe that the bleaching agents are meant 
for cleansing, beautification, promoting attractiveness or altering the appearance of the users without affecting the body's structure and function [6].

Identified constituents of skin lightening creams include mercury, hydroquinone, kojic acid, azleic acid, arbutin, vitamin C, magnesium ascorbyl phosphate, calcium ascorbate and ascorbyl glucoside [7, 8]. Other lightening products may have niacinamide (vitamin B), licorice extract, chromabright, azelaic acid aleossin from aloevera plant, kojic acid, alpha arbutin, beta arbutin, ascorbyl glucoside or magnesium ascorbyl phosphate, mulberry extract, glycoric acid, licorine extract, niacinamidel lactic acid, lemon juice extract, emlica, potato and turmeric. Such chemicals are capable of inhibiting the enzyme(s) in the tyrosine-melanin pathway, via different mechanisms $[9,10,11]$. In the past, the quickest way to lighten skin was with hydroquinone. But since this active ingredient has toxic effects, it has been banned in many countries across Africa and Europe [12]. A study by California medical officials on some facial lightening creams contained mercury levels of 20,000 to $56,000 \mathrm{ppm}$ [13]. Claudia et al. [14] recorded levels of mercury between 878 and 36,000 ppm in six lightening creams studied in Mexican. In Saudi Arabia a study by Al-Ashban et al. [15] on skin lightening creams recorded levels of mercury between 2.46 to 23222 ppm; while Voegborio et al., [16] in the same country recorded mercury levels between 1.18 to 5650 ppm in 17 skin lightening cream samples. In Kenya, a study by Maina [17] showed that levels of mercury in seven different brands of skin lightening creams significantly higher. Skin lightening is currently one of the most common forms of potentially harmful body modification practices causing metabolic dysfunctions and cancer in the users [18]. It was then recommended that the manufacturers should be informed about the hazards of high concentrations of mercury, since various local bleaching creams have no identified active agent [19]. Considering the toxic effects of the active chemical constituents of bleaching creams, levels above maximum permissible limits would be harmful to both skin and other organs. The allowable levels of active chemical constituents of bleaching creams are $2 \%$ by weight for hydroquinone, $1 \mathrm{ppm}$ for mercury, $3 \%$ by weight for magnesium ascorbyl phosphate, $2 \%$ by weight for ascorbyl glucoside, $2 \%$ by weight for kojic acid and $7 \%$ by weight for arbutin in skin care products $[3,20]$. Mercury is a heavy metal that has higher than 3 $\mathrm{g} / \mathrm{cm} 3$ densities and has biological effects at low concentrations and is toxic when present in cells at higher than the tolerable physiological levels $[21,22]$. There is limited information on the levels of heavy metals in ointments and creams used for skin bleaching in Nigeria. Therefore, this study was designed to determine the levels of mercury, lead, cadmium, chromium and arsenic in commonly used bleaching creams in Nigeria.

\section{MATERIALS AND METHODS}

\section{Materials:}

Twelve different types of skin lightening creams (Extra white, Make me white, Extract, Perfect white, UV lightening, Pure skin, Body treat, Dodo up, Bronze tone, White express, Peau Claire and Otentika) being used by young adult females in Lagos, Nigeria were randomly collected based on their usage and availability. Another three non- lightening creams such as Vaseline were purchased from a supermarket. Levels of mercury, lead, cadmium, chromium and arsenic were determine

\section{Cleaning of apparatus}

All apparatus were soaked in detergent solution overnight, rinsed and soaked in $10 \%$ analytical grade nitric acid overnight before being rinsed with distilled water. The glasswares were dried in an oven at $105^{\circ} \mathrm{C}$.

\section{Chemical, reagents and solvents for preparation of sample}

Analytical grade of concentrated nitric acid $\left(\mathrm{HNO}_{3}\right)$, Hydrochloric acid, Distilled water. 


\section{Sample preparation / digestion}

A $20 \mathrm{~mL}$ of freshly prepared acid mixture of concentrated nitric and hydrochloric acid (ratio 3:1) was added to $1.0 \mathrm{~g}$ of cream. The conical flask was covered and mixture heated at $200^{\circ} \mathrm{C}$ until there was no brown fume produced. The solution was cooled, made up to the mark using distilled water then filtered using Whatman paper (Number 1).

\section{Analysis of Sample:}

Atomic absorption spectrophotometer with mercury vaporizer unit (model MVU-IA) was used to analyze the samples using the method of Kaneko et al [23].

\section{Statistical Analysis:}

All statistical analyses were performed using Statistical Package for Social Sciences (SPSS), version 21.0. The data were expressed as Mean \pm SD. Student $(t)$ test was used for comparison of analytes in lightening creams and controls. P-values less than 0.05 were considered significant.

\section{Results and Discussion}

All lightening creams analyzed contained significantly higher levels of mercury compared with the nonlightening creams (controls) as shown in Table 1. Higher levels of mercury observed in all lightening creams might be due to inorganic mercury such as ammoniated mercury and mercuric iodide used as ingredients of the skin lightening creams [24]. Higher levels of mercury observed in our lightening creams despite the allowable level of $1 \mathrm{ppm}$ for cosmetics approved by WHO $[3,20]$, could expose the users to toxic concentrations of mercury.

The form of mercury plays a role in how much is absorbed via dermal or oral routes. Organic (methyl) mercury is of greater concern than inorganic mercury; however, all forms of mercury are absorbed through the skin and mucosa, and dermal exposure can result in systematic toxicity. For the general population, the major route of mercury exposure is dietary intake. Mercury compounds may cause allergic reactions, skin irritation, or adverse effects on the nervous system. Clinical symptoms of overexposure to mercury include tremors, weakness, memory loss, dermatitis and impaired kidney function, with the form of mercury typically determining the specific symptoms.

Several studies have reported the possible pathological consequences of mercury toxicity in the exposed individuals. Bingol and Ackay [25], Al-Saleh [7] and Barrat et al. [26] reported that chronic exposure to either inorganic or organic mercury may damage the brain, kidneys, nervous system and developing foetus. A high concentration of mercury in pregnant women is known to considerably increase the risk of permanent brain damage and may lead to acrodymia (pink baby syndrome). Exposure of mercury to placental cells causes damage to the developing fetus $[25,27]$. Chronic exposure to either inorganic or organic mercury may damage brain, kidneys, nervous system and developing foetus [26]. By inhibiting the production of melanin, the skin is more susceptible to skin cancer. Nephro- toxic effects have been attributed to application of inorganic mercury salts. Exposure of mercury to placental cells causes damage to the developing foetus $[25,27]$. In other studies $[28,29]$, observed that complications of mercurial toxicity include exogenous ochronosis, dermatitis, facial acnes, facial hypertricosis, hyper and hypo-pigmentation, reduction in the skin resistance to bacterial and fungal infections, anxiety, depression, psychosis, impaired wound healing, the fish odour syndrome, nephropaty, steroid addition syndrome and predisposition to infections. 
Table 1: Levels of Mercury $(\mu \mathrm{g} / \mathrm{g})$ in Bleaching Creams and Non-Bleaching Cream (Control)

\begin{tabular}{|c|c|c|c|c|}
\hline Name of Cream & Control & lightening Cream & t-test & $p$-values \\
\hline Extra white & $366.7 \pm 57.7$ & $1733.3 \pm 115.5$ & 18.3 & $<0.001(\mathrm{~S})$ \\
\hline Make me white & $366.7 \pm 57.7$ & $1400 \pm 200$ & 8.6 & $0.01(S)$ \\
\hline Extract & $366.7 \pm 57.7$ & $1933 \pm 115.5$ & 21 & $<0.001(\mathrm{~S})$ \\
\hline Perfect white & $366.7 \pm 57.7$ & $2200 \pm 200$ & 15.3 & $<0.001(\mathrm{~S})$ \\
\hline UV lightening & $366.7 \pm 57.7$ & $1666.7 \pm 305.5$ & 7.2 & $0.002(S)$ \\
\hline Pure skin & $366.7 \pm 57.7$ & $1466.7 \pm 115.5$ & 4.0 & $0.016(S)$ \\
\hline Body treat & $366.7 \pm 57.7$ & $1733.3 \pm 115.5$ & 18.3 & $<0.001(S)$ \\
\hline Dodo up & $366.7 \pm 57.7$ & $2333.3 \pm 305.5$ & 11.0 & $<0.001(S)$ \\
\hline Bronze tone & $366.7 \pm 57.7$ & $2066.7 \pm 115.5$ & 22.8 & $<0.001(\mathrm{~S})$ \\
\hline White express & $366.7 \pm 57.7$ & $1333.3 \pm 230.9$ & 7.0 & $0.002(S)$ \\
\hline Peau Claire & $366.7 \pm 57.7$ & $1333.3 \pm 115.5$ & 13 & $<0.001(\mathrm{~S})$ \\
\hline Otentika & $366.7 \pm 57.7$ & $1133.3 \pm 115.5$ & 10 & $0.001(\mathrm{~S})$ \\
\hline
\end{tabular}

The concentrations of lead in the creams showed that only Otentika did not contain significant $(p>0.05)$ amount of lead (Table 2) compared with the controls. However, sufficient evidence shows that blood lead levels $<5 \mu \mathrm{g} / \mathrm{dL}$ are associated with decreased renal function and that blood lead levels $<10 \mu \mathrm{g} / \mathrm{dL}$ are associated with increased blood pressure and hypertension [30]. Other bleaching creams have significantly $(p<0.05)$ higher levels of lead compared to the control cream. Although, inorganic lead in the creams crosses the skin less readily with a low permeability co-efficient of about 10-4 cm/hour, prolonged exposure to lead from cosmetics might lead to lead accumulation in the tissues. Previous studies show that lead exerts adverse effects on numerous organs and metabolic pathways including the central nervous system, kidneys and on the heme synthetic pathway. Other studies show that exposure to lead results in neurological disorders, infertility and hypertension [30].

Table 2: Levels of lead $(\mu \mathrm{g} / \mathrm{g})$ in Bleaching Creams and Non-Bleaching Cream (Control)

\begin{tabular}{|c|c|c|c|c|}
\hline Name of Cream & Control & lightening Cream & t-test & $p$-values \\
\hline Extra white & $466.7 \pm 115.5$ & $1000 \pm 200$ & 4.0 & $0.016(S)$ \\
\hline Make me white & $466.7 \pm 115.5$ & $733.3 \pm 115.5$ & 2.8 & $0.047(\mathrm{~S})$ \\
\hline Extract & $466.7 \pm 115.5$ & $1333.3 \pm 115.5$ & 4.6 & $0.010(\mathrm{~S})$ \\
\hline Perfect white & $466.7 \pm 115.5$ & $1133.3 \pm 115.5$ & 7.1 & $0.002(S)$ \\
\hline UV lightening & $466.7 \pm 115.5$ & $1200 \pm 200$ & 5.5 & $0.005(\mathrm{~S})$ \\
\hline Pure skin & $466.7 \pm 115.5$ & $1000 \pm 200$ & 4.0 & $0.016(\mathrm{~S})$ \\
\hline Body treat & $466.7 \pm 115.5$ & $1133.3 \pm 115.5$ & 7.1 & $0.002(S)$ \\
\hline Dodo up & $466.7 \pm 115.5$ & $1266.7 \pm 115$ & 8.5 & $0.001(\mathrm{~S})$ \\
\hline Bronze tone & $466.7 \pm 115.5$ & $1666.7 \pm 115.5$ & 12.7 & $<0.001(S)$ \\
\hline White express & $466.7 \pm 115.5$ & $1066.7 \pm 115.5$ & 6.4 & $0.003(S)$ \\
\hline
\end{tabular}




$\begin{array}{lllll}\text { Peau Claire } & 466.7 \pm 115.5 & 733.3 \pm 115.5 & 2.8 & 0.047(\mathrm{~S}) \\ \text { Otentika } & 466.7 \pm 115.5 & 800 \pm 200 & 2.5 & 0.067 \text { (NS) }\end{array}$

Levels of cadmium did not increase significantly in eight of the creams (Make me white, Extract, Perfect white, UV lightening, Pure skin, Body treat, White express and Otentika) compared with the controls. Meanwhile, four bleaching creams (Extra white, Perfect white, Dodo up and Peau Claire) demonstrated significantly $(p<0.05)$ higher level of cadmium compared with the controls (Table 3). Although, absorption of cadmium through the skin is low $(0.5 \%)$ and would be of concern only in situations where concentrated solution is in contact with the skin for several hours or longer. Cadmium binds to epidermal keratin when applied topically, thus explaining the limited dermal absorption observed in vitro. Several studies have implicated cadmium in many metabolic disorders and organ dysfunctions. Cadmium is classified as a human carcinogen by the National institute for Occupational Safety and Health [31].

\section{Table 3: Levels of cadmium $(\mu \mathrm{g} / \mathrm{g})$ in Bleaching Creams and Non-Bleaching Cream (Control)}

\begin{tabular}{|c|c|c|c|c|}
\hline Name of Cream & Control & lightening & Cream & $p$-values \\
\hline Extra white & $100 \pm 20$ & $400 \pm 25.0$ & 3.7 & $0.002(S)$ \\
\hline Make me white & $100 \pm 20$ & $266.7 \pm 15.5$ & 2.5 & $0.007(S)$ \\
\hline Extract & $100 \pm 20$ & $200 \pm 15.6$ & 2.4 & $0.008(S)$ \\
\hline Perfect white & $100 \pm 20$ & $333.3 \pm 115.5$ & 3.5 & $0.025(\mathrm{~S})$ \\
\hline UV lightening & $100 \pm 20$ & $266.7 \pm 35.5$ & 2.5 & $0.067(S)$ \\
\hline Pure skin & $100 \pm 20$ & $90.0 \pm 40.0$ & 0.16 & 1.20 (NS) \\
\hline Body treat & $100 \pm 20$ & $266.7 \pm 25.5$ & 2.5 & $0.017(S)$ \\
\hline Dodo up & $100 \pm 20$ & $333.3 \pm 115.5$ & 3.5 & $0.025(\mathrm{~S})$ \\
\hline Bronze tone & $100 \pm 20$ & $466.7 \pm 115.5$ & 5.5 & $0.005(\mathrm{~S})$ \\
\hline White express & $100 \pm 20$ & $78.0 \pm 37.7$ & 0.20 & 1.37 (NS) \\
\hline Peau Claire & $100 \pm 20$ & $333.3 \pm 50.5$ & 3.5 & $0.025(\mathrm{~S})$ \\
\hline Otentika & $100 \pm 20$ & $266.7 \pm 15.8$ & 2.5 & $0.67(S)$ \\
\hline
\end{tabular}

As shown in Table 4, one of the bleaching creams (Peau Claire) did not have detectable level of arsenic. But significantly $(p<0.05)$ higher levels of arsenic were observed in eleven bleaching creams compared with controls. Previous studies show that exposure through water, industrial sources, toxic waste sites and traditional medicines predispose people to arsenic. Since arsenic has pronounced affinity for skin and keratinizing structures including the hair and nails, the present study could implicate the use of skin bleaching creams as another route of exposure to arsenic. Available information show that arsenite inhibits the formation of acetyl$\mathrm{CoA}$, and succinic dehydrogenase. Many reports show that arsenate can replace phosphate in many reactions to form glucose-6-arsenate in vitro. It has been hypothesized that hexokinase could be inhibited in the glycolytic pathway $[32,33]$. 
Table 4: Levels of arsenic $(\mu \mathrm{g} / \mathrm{g})$ in Bleaching Creams and Non-Bleaching Cream (Control)

\begin{tabular}{|c|c|c|c|c|}
\hline Name of Cream & Control & lightening & Cream t-test & $\mathrm{p}$-values \\
\hline Extra white & 0.00 & $333.3 \pm 115$ & 5.0 & $0.007(\mathrm{~S})$ \\
\hline Make me white & 0.00 & $266.7 \pm 115.5$ & 4.0 & $0.016(S)$ \\
\hline Extract & 0.00 & $466.7 \pm 115.5$ & 7.0 & $0.002(S)$ \\
\hline Perfect white & 0.00 & $333.3 \pm 115.5$ & 5.0 & $0.007(S)$ \\
\hline UV lightening & 0.00 & $466.7 \pm 115.5$ & 7.0 & $0.002(\mathrm{~S})$ \\
\hline Pure skin & 0.00 & $400.0 \pm 58.0$ & 6.8 & $0.002(S)$ \\
\hline Body treat & 0.00 & $400 \pm 200.0$ & 3.5 & $0.026(\mathrm{~S})$ \\
\hline Dodo up & 0.00 & $266.7 \pm 115.5$ & 4.0 & $0.016(S)$ \\
\hline Bronze tone & 0.00 & $200.0 \pm 31.0$ & 4.0 & $0.016(S)$ \\
\hline White express & 0.00 & $333.3 \pm 115.5$ & 5.0 & $0.007(S)$ \\
\hline Peau Claire & 0.00 & 0.00 & $\ldots$ & $\ldots$ \\
\hline Otentika & 0.00 & $200.0 \pm 27.00$ & 4.0 & $0.016(S)$ \\
\hline
\end{tabular}

Chromium has been implicated in the generation of free radicals, including DNA damage [34] and formation of stable DNA-chromium complexes, DNA strand breaks, DNA-DNA cross links, and DNA-protein cross links [35]. Reports show that dermatitis, allergic and eczematous skin reactions, skin and mucous membrane ulcerations, perforation of the nasal septum, allergic asthmatic reactions, bronchial carcinomas, gastro-enteritis and hepatocellular dysfunction occur after contact, inhalation, or ingestion of hexavalent chromium compounds [36]. In this study, Significantly $(p<0.05)$ higher levels of chromium were observed in four bleaching creams; UV lightening, Body treat, Dodo up and Bronze tone when compared with the control cream (Table 5). Chromium was not detectable in eight of the bleaching creams (White express, Peau Claire, Otentika, Pure skin, Perfect white, Extract, Make me white and Extra white). In this study, chromium may not be considered as a major constituent of bleaching creams.

Table 5: Levels of chromium ( $\mu \mathrm{g} / \mathrm{g})$ in Bleaching Creams and Non-Bleaching Cream (Control)

\begin{tabular}{|c|c|c|c|c|c|}
\hline Name of Cream & Control & lightening & Cream & t-test & $p$-values \\
\hline Extra white & 0.00 & 0.00 & & 0.00 & (NS) \\
\hline Make me white & 0.00 & 0.00 & & 0.00 & (NS) \\
\hline Extract & 0.00 & 0.00 & & 0.00 & (NS) \\
\hline Perfect white & 0.00 & 0.00 & & 0.00 & (NS) \\
\hline UV lightening & 0.00 & $200.0 \pm 65$ & & 7.0 & $0.007(S)$ \\
\hline Pure skin & 0.00 & 0.00 & & 0.00 & (NS) \\
\hline Body treat & 0.00 & $266.7 \pm 115.5$ & & 4.0 & $0.016(\mathrm{~S})$ \\
\hline
\end{tabular}




$\begin{array}{lllll}\text { Dodo up } & 0.00 & 266.7 \pm 115.5 & 4.0 & 0.016(\mathrm{~S}) \\ \text { Bronze tone } & 0.00 & 333.3 \pm 115.5 & 5.0 & 0.007(\mathrm{~S}) \\ \text { White express } & 0.00 & 0.00 & 0.00 & \text { (NS) } \\ \text { Peau Claire } & 0.00 & 0.00 & 0.00 & \text { (NS) } \\ \text { Otentika } & 0.00 & 0.00 & 0.00 & \text { (NS) }\end{array}$

It could be concluded that mercury, cadmium, lead and arsenic are common constituents of lightening creams marketed in Nigeria. To avert the risk and consequences of metal toxicity in the users of the lightening agents, levels of toxic metals should be monitored officially in creams and cosmetics. The manufacturers should be educated about the potential risks associated with higher levels of these metals. This study could therefore provide valuable information for health researchers and policy makers.

\section{Authors' contributions:}

MOA, OBS, LEAand SOA designed the research, MOA and LEA did the analysis and all authors contributed and approved the final manuscript.

Conflict of interests: The authors declared that they have no competing interests.

Funding statement: The study was self sponsored.

Acknowledgement: The authors appreciate Mr. J. Abegunde of the Department of Chemistry and Biochemistry, Caleb University Lagos for the technical and material supports.

\section{References:}

1. Adeyeye El and Abulude FO (2004). Analytical assessments of some surface and ground water resources in Ile-Ife, Nigeria. J. Chem. Soc. Nig. 29: 98-103.

2. Nelson Andrew A, Tsao Hensin (2009). "Melanoma and genetics". Clin. Dermatol. 27 (1). doi:10.1016/j.clindermatol.2008.09.005. PMID 19095153. Restricted access.

3. WHO (2007). Exposure to mercury: A major public health concern. Geneva, World Health Organisation (Preventing disease through healthy environment).

4. Adebayo BS, (2008), Incidence, Consequences and attitude towards cosmetic -skin bleaching as expressed by secondary school students in Lagos, Nigeria. An M.Ed. project submitted to the University of Ilorin, Nigeria

5. Sin KW and Tsang, HF (2003) Large scale mercury exposure due to a cream cosmetics:Community wide case series. Hong Kong Medical Journal, 9: 329-334.

6. Liesl JT (2006). Specific cosmetic and skincare needs of women of colour in South Africa. Journal of Somatology, 3: 18-36.

7. Al-Saleh I, El-Doush I, Shinwari N, Al-Baradei R, Khogali F and Al-Amodi M. (2005). Mercury content in skinlightening creams and potential hazards to the health of Saudi women. Journal of Toxicology and Environmental Health, 51: 123-130.

8. Lai JS, Kuo HW, Liao FC, Lien CH (1998). Sister chromatid exchange induced by chromium compounds in human lymphocytes. Int. Arch. Occup. Environ. Health. 71, 550-553.

9. Olumide YM, Akinkugde AO. and Altraide D (2010). Complications of chronic use of skin lightening cosmetics. International Journal Dermatology, 47: 344-53. 
10. Yetunde, M, Ayesha O, Ayanlowo S, Onyekonwu O and Nyomudim E (2008). Complications of chronic use of skin lightening cosmetics. International Journal of Dermatology, 7: 344-353.

11. Amanda $O$ (2011). Skin lightening and depigmeting agents. Journal of Human Toxicology, 6: 253-256.

12. Mariko Matsumoto, Hiroaki Todo, TakumiAkiyama, MutsukoHirata-Koizumi, KenjiSugibayashi, Yoshiakil karashi, Atsushi Ono, Akihiko Hirose, Kazuhito Yokoyama (2016). Risk assessment of skin lightening cosmetics containing hydroquinone. Regulatory Toxicology and Pharmacology. 81, 128-135.

13. Melisa CS and Jay WM (2009). FDA Proposes Hydroquinone Ban. Journal of Culture and Africa Women Studies, 14: 5-16.

14. Claudia P, Myriam VM, Silvia VM, Alma DR and Luz OL (2011). Mercury levels in locally manufactured Mexican skin lightening creams. International Journal of Environmental Research, 8; 2516-2523.

15. Al-Ashban RM, Barratt DA and Shah AH (2006). Mercury contents of skin lightening creams marketed in Saudi Arabia Journal of Saudi Chemist Society, 10 (2): pp. 383-388.

16. Voegborio BB, Argorku SE, Buubeng-Acheampong B and Zogil E (2008). Total mercury content of skin toning creams and the pontential risk to the health of women in Ghana. Journal of Science and Technology, 28 (1): 88-97.

17. Maina C (2013). A simple non-destructive technology for the analysis of mercury in creams in Kenya. Journal of Pharmacy and Pharmacology, 2: 23-45.

18. Lewis KM (2011). Investigating motivations for women's skin bleaching in Tanzania. Psychology of Women Quarterly, 35: (29):29-37.

19. Mahe A, Ly F, Aymard G, Dangou JM (2003). Skin diseases associated with the cosmetic use of bleaching products in women from Dakar, Senegal. Br J Dermatol.148:493-500.

20. DHEY (2000). Department of Health, Executive Yuan.Ordinance No. 89028104. Taipei. (Chinese).

21. Banfalvi G (2011). Cellular effects of heavy metals. Springer UK. Pp. 6-13.

22. Rai S, Shirma D, Kr, Arora SS, Sharma M and Chopra AK (2011). Concentrations of heavy metals in Aloe vera L. (Aloe barbadensis Miller) leaves collected from different geographical locations of India. Annals of Biological Research, 2:575-579.

23. 23. Kaneko J.J (1999). Clinical Biochemistry of Animal.4th Edition.Academic Press Inc. Pp 932.

24. Ladizinski B, Mistry N, Kundu RV (2010). Widespread use of toxic skin lightening compounds: medical and psychosocial aspects. Dermatol Clin. 2011 (1):111-23. doi: 10.1016/j.det.2010.08.010.

25. Bingol D and Akcay M (2005). Determination of trace elements in fly ash samples by AAS after applying different digestion procedure. Quantitative Spectroscopy and Radiative Transfer Journal, 101: 146-150.

26. Barrat DA, Al-Ashban RM and Shah AH (2006). Mercury contents of skin lightening creams marketed in Saudia Arabia. Journal Saudi Chemical Society, 10: 383-388.

27. Kinabo CP (2003) Comparative analysis of mercury content in human hair and cosmetics products used in Dar es salaam, Tanzania Journal of pharmacy and pharmacology, 2: 23-45.

28. Doreen A (2010). Levels of hydroquinone and mercury in skin lightening creams and their potential risk to the health of consumers in Ghana (MSc Thesis).

29. Oyelakin O, Saidykhan J1, Secka P, Adjivon1 A and Acquaye HB (2010). Assessment of the Level of Mercury Present in Soaps by the Use of Cold Vapour Atomic Fluorescence Spectrometric Analysis. Ethiopian Journal of Environmental Studies and Management, 3 (1):178-199.

30. National Toxicology Program (2012). Monograph on Health Effects of Low-Level Lead. Research Triangle Park, NC. [updated 2012 June; accessed 2016 Sept. 23]. Available from: https://ntp.niehs.nih.gov/?objectid=4F04B8EA-B187-9EF2-9F9413C68E76458E. 
31. Kristin Seidal, Nils Jörgensen, Carl-Gustaf Elinder, Bengt Sjögren and Marie Vahter (1993). Fatal cadmiuminduced pneumonitis. Scandinavian Journal of Work, Environment \& Health 19, 6: 429-431

32. Andersen $\mathrm{O}$, Aaseth $J$ (2016). "A review of pitfalls and progress in chelation treatment of metal poisonings". Journal of Trace Elements in Medicine and Biology. 38: 7480. doi:10.1016/j.jtemb.2016.03.013. hdl:11250/2430866. PMID 27150911.

33. Naujokas MF, Anderson B, Ahsan H, Aposhian HV, Graziano JH, Thompson CS, William A (2013). "The Broad Scope of Health Effects from Chronic Arsenic Exposure: Update on a Worldwide Public Health Problem". Environmental Health 302. doi:10.1289/ehp.1205875. PMC 3621177. PMID 23458756.

34. ATSDR (2018). Toxic Pubstances Portal: Lead." https://www.atsdr.cdc.gov/substances/toxsubstance.asp?toxid=22

35. Meditext - Medical Management (2005). "Chromium Hexavalent Salts." TOMES Information System. Denver, CO: Micromedex, Inc.

36. Baruthio F (1992).Toxic effects of chromium and its compounds. Biol Trace Elem Res. 32:145-53. 